\title{
A Numerical Model for Predicting Dynamic Performance of Biomass-Integrated Organic Rankine Cycle, ORC, System for Electricity Generation
}

\author{
Samuel Sami, Edwin Marin \\ Research Center for Renewable Energy, Catholic University of Cuenca, Cuenca, Ecuador
}

Email address:

dr.ssami@transpacenergy.com (S. Sami)

To cite this article:

Samuel Sami, Edwin Marin. A Numerical Model for Predicting Dynamic Performance of Biomass-Integrated Organic Rankine Cycle, ORC, System for Electricity Generation. American Journal of Energy Engineering. Vol. 4, No. 3, 2016, pp. 26-33. doi: 10.11648/j.ajee.20160403.11

Received: June 29, 2016; Accepted: July 13, 2016; Published: August 10, 2016

\begin{abstract}
This paper presents the modeling of the energy conversion equations describing the total power generated by a hybrid system of biomass-CHP (Combined Heat and Power) and Organic Rankine Cycle (ORC). A numerical model based upon the aforementioned conservation equations was developed, coded and results were analyzed. The model is intended to be used as an optimization and design tool for typical Biomass-CHP systems. The proposed model predicted results compared fairly with data under various biomass loading conditions.
\end{abstract}

Keywords: Integrated-Biomass System, CHP, ORC, Modeling, Simulation, Experimental Validation

\section{Introduction}

Renewable and nonconventional methods of power generation such as wind, solar, hydraulic, biomass, geothermal, thermal storage and waste heat recovery power generations offer power supply solutions for remote areas that are inaccessible to the grid power supply [1-4].

Mustafa [5] presented and discussed the electrification of rural area and a review of power standalone system such as: solar and hybrid, solar-wind, solar-hydro hybrid, solar-winddiesel hybrid, and solar-wind-diesel-hydro/biogas. In addition, references [5-7] presented and analyzed the viability and importance of solar energy use in global electrification. Furthermore, Fargali et al. [8] presented a biomass and geothermal space heating system that buses PVwind to feed the electrical load in different buildings in a remote area. Their study included mathematical modeling and MATLAB Simulink model. Mutafa [9], presented a proposed algorithm for sizing and simulation of various power systems including PV-Wind hybrid power system that can simulate the annual performance of different kinds of these systems structures.

Incineration is one the most effective biomass technologies for municipal waste disposal, however, it involves pollution that results from the combustion process. Combustion gas is generated at the bed combustion where it passes through the furnace combustion chamber to complete the combustion process with all reactive gases. The gas in the drying and pyrolysis zone is cold, however, flue gases from combustion chamber zone are hot. These gases are mixed up in the furnace chamber and induced radiative energy is mixed up with the waste material and wall in the furnace. Therefore, the main heat and mass transfer in the furnace combustion chamber are radiation, convection, conduction and moist content evaporation. All of these heat and mass transfer must be considered in incinerator's study.

Various studies have focused on emission reduction in incinerators, Choi et al. [10, 11, 12]. A process simulation model for $2 \mathrm{ton} / \mathrm{hr}$ incinerator (a combined bed combustion and furnace heat transfer model) has been presented by Yang et al. [11], however, the principal author [12], also presented a useful study on the improvement of operating conditions in waste incinerators using engineering tools. In their study, one dimensional model for heat and mass balance, computational fluid dynamics CFD and global prediction model and observation model for dioxin are employed. Furthermore, sophisticated solutions dealing with incinerators such as realtime simulators for predictive performance of incinerators 
were presented by Gan et al [13]. On the other hand, several mathematical model have been presented on the modeling of Organic Rankine Cycle by Sami [14-16, 17, 18], where the energy conversion process from waste heat to power have been modeled using refrigerant mixtures.

The implementation of the ORC process into the overall power plant results in efficient high production of electric energy. In particular, an integrated ORC Biomass process provides simultaneously secure supply of electrical energy and steam-water and/or hot water feed to buildings and district heating applications. Therefore, this paper is concerned with the main heat and mass transfer mechanisms in the furnace combustion chamber such as convection, conduction and moist content evaporation as well as the analysis of the biomass-CHP integrated ORC systems. A numerical simulation using one dimensional model is presented hereby to describe the biomass incineration-CHP process and its performance

\section{Mathematical Modeling}

In the following sections, the energy conversion equations for each source of renewable energy to an electrical energy are presented.

\section{Biomass Incinerator}

The physical phenomena occurring in the incineration chamber starts with the incineration process above the grate. The waste is heated up and goes through pyrolysis, volatile reactions, char and ash cooling. The combustion gas generated from the bed combustion goes through the furnace chamber to complete the combustion process. Furthermore, the different gases from the combustion process are mixed up in the furnace chamber and exchange radiative energy with the waste material bed and furnace wall (C. F. Figure 1). The heat transfer mechanisms taking place inside the combustion chamber are radiation, convection, conduction and evaporation $[11,12]$.

In the following the heat and mass transfer model is presented for the incinerator furnace model. The flue gas is released after the waste combustion bed. The radiation is the major heat transfer by-product because of the high temperature of the gas. However, other heat transfer mechanisms are present in the furnace heat transfer such as convective, evaporation and combustion and must be taken in consideration in order to solve the energy conversion equations of biomass incinerators [11-14];

$$
Q_{\text {adrin }_{\text {gas }}}-Q_{\text {adrout }_{\text {gas }}}=Q_{\text {comb }}+Q_{\text {rad }}-Q_{\text {conv }}-Q_{\text {evap }}
$$

Where;

$$
\begin{gathered}
Q_{\text {adringas }_{\text {gas }}}-Q_{\text {adrout }}=m_{\text {gas }} C_{p_{\text {gas }}}\left(T_{\text {out }}-T_{\text {in }}\right) \\
Q_{\text {add }}=4.18 C V_{\text {bio }} m_{\text {bio }} \eta_{\text {heater }} \\
Q_{\text {conv }}=h_{w} A_{\text {wall }}\left(T_{\text {gas }}-T_{\text {well }}\right)
\end{gathered}
$$

$$
\begin{gathered}
Q_{\text {rad }}=E_{g} A\left(T 4_{a}-T 4_{\text {bed }}\right) \\
Q_{\text {evap }}=\eta_{\text {water }} H_{\text {evap }}
\end{gathered}
$$

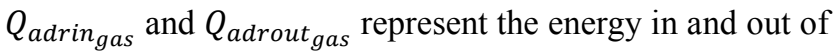
the furnace chamber, respectively.

The hot flue gas emitted from the incinerator combustion chamber is coupled with a thermal oil loop and Organic Rankine Cycle (ORC) to generate refrigerant vapor at the waste heat boiler as shown in Figure 1. The Organic Rankine Cycle, (ORC) is a Rankine Cycle that uses a heated chemical instead of steam as found in the conventional Rankine Cycle. Non organic and organic fluids are used in Organic Rankine cycles. Theoretical performances as well as thermodynamic and environmental properties of few fluids have been comparatively assessed for use in low-temperature organic Rankine cycle systems by Sami [16].

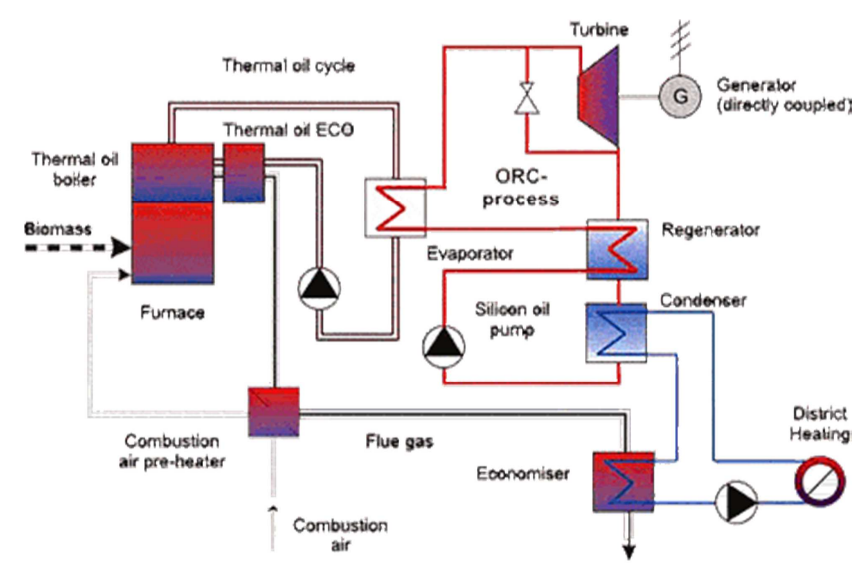

Figure 1. Biomass integrated ORC/CHP system [16, 17].

Readers interested in further details of the efficient use of ORC where a vapor turbine generator unit is used to generate electricity as shown in Figure 1 are advised to consult reference Sami [16]. The flue gas from the incinerator combustion chamber heats up the thermal oil in the heat exchanger heater and exits to the ambient at lower temperature to reduce its impact on the environment since the thermal oil heat exchanger tank acts as a scrubber. The heated thermal oil is circulated to the waste heat boiler (WHB) of the ORC where the refrigerant vapor is generated. The saturated or slightly superheated vapor expands in the vapor turbine of the ORC, where electricity is generated at the generator end of the vapor turbine and supplied to the grid through switch gear. The expanded low pressure is condensed in the condenser and pumped to the WHB to compete the ORC cycle [16]. It has been reported by Sami [16] that the ORC performance can be enhanced significantly by using refrigerant mixtures. This study employs refrigerant mixtures in the analysis of the ORC. The following thermodynamic equations can be written to evaluate the performance of the ORC [16];

$$
\begin{gathered}
W_{O R C}=\eta_{T G U} m_{r e f}\left(h_{1}-h_{2}\right) \\
Q_{W H B}=\eta_{W H B} m_{r e f}\left(h_{1}-h_{4}\right)
\end{gathered}
$$


Heat balance at the ORC is as follows;

$$
\begin{gathered}
m_{\text {oil }} C_{p_{\text {oil }}}\left(T_{d}-T_{L}\right)=m_{\text {ref }}\left(h_{1}-h_{2}\right)-\mathrm{Q}_{\mathrm{c}}-\mathrm{W}_{\mathrm{p}} \\
\eta_{\text {ORC }}=\frac{W_{O R C}}{Q_{W H B}}
\end{gathered}
$$

Equation (10) defines the net biomass ORC efficiency that includes all losses and power consumed by accessories of the biomass combined heat and power hybrid system. The thermodynamic properties of the refrigerant circulating on the ORC is determined by REFPROP [16].

The energy balance on the bio-mass flue gas thermal oil heater $[8,15]$ can be used to estimate the thermal oil temperature time-variation in the heater tank;

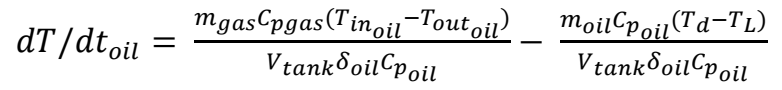

Where,

$Q_{\text {comb }}$ : Combustion heat added

$Q_{\text {rad }}$ : Radiative heat

$Q_{\text {conv }}$ : Convective heat

$Q_{\text {evap }}$ : Evaporative heat

$\mathrm{Q}_{\mathrm{c}}$ : Heat released by condenser

$\mathrm{T}$ : is the temperature thermal oil in heat exchanger tank

$\delta_{\text {oil }}$ : Density of thermal oil

$V_{\text {tank }}$ : Volume of heater

$m_{\text {gas }}$ : Mass flow rate of flue gas

$m_{\text {bio }}$ : Biomass waste mass material

$m_{\text {ref }}$ : Mass flow rate ORC cycle refrigerant

$W_{O R C}:$ Work generated at ORC vapor turbine generator

$\eta_{\text {ORC }}$ : ORC thermal efficiency

The Biomass-CHP energy conversion efficiency of the hybrid system can be obtained by;

$$
\eta_{\text {Biomass }}=\frac{W_{\text {ORC }}}{Q_{\text {comb }}}
$$

Where $Q_{\text {comb }}$ is defined as follows;

$$
Q_{\text {comb }}=4.18 C V_{\text {bio }} m_{\text {bio }} \eta_{\text {bio }}
$$

Where;

$C V_{\text {bio }}$ : Calorific heat value of bio-gas

$\eta_{\text {bio }}$ : Biomass furnace efficiency

Numerical Procedure

The energy conversion and heat transfer mechanisms taking place during various processes shown in Figure 1, are described in Equations (1) through (13). These equations have been solved as per the logical flow diagram presented in Figure 2, where the input parameters of Biomass, as well as the ORC and independent parameters are defined. Dependent parameters were calculated and integrated in the system of finite-difference formulations. Iterations were performed until a solution is reached with acceptable iteration error.

The numerical procedure starts with using the biomass loading to calculate the mass flow rate of flue gas, thermal oil, and refrigerant circulating in various loops under specified conditions. The thermodynamic and thermophysical properties of flue gas, thermal oil, and refrigerant are determined based upon the initial conditions of the biomass incinerator loading, lower heating value, air flow rate, excess air ratio, and combustion products. This follows by using the finite-difference formulations to predict the time variation of the oil tank temperature as well as other hybrid system power outputs and efficiencies. Finally, hybrid system efficiency is calculated at each input condition.

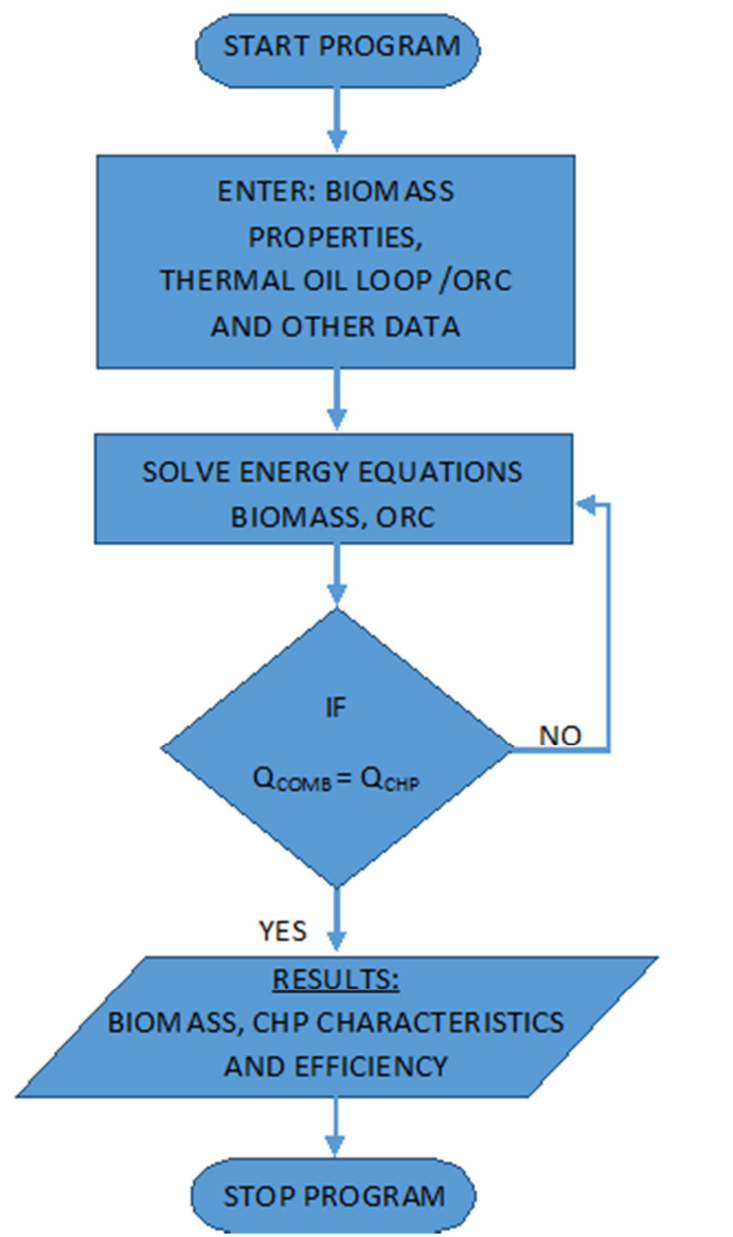

Figure 2. Flow diagram of Hybrid system; biomass and CHP calculation.

\section{Results and Discussion}

In order to solve the aforementioned equation (1) through (13) and, taking into account that total power may not be simultaneous, and for validation purposes, this simulation model and the above mentioned equations were coded with finite-difference formulations. In addition, for the purpose of validation and tuning up the predicted output simulated results, the data was used to validate the simulation program under various conditions. In the following sections, we present analysis and discussions of the numerical results predicted as well as validations of the proposed simulation model.

\subsection{Biomass Simulation}

Equations (1) through (13) present the heat and mass calculation balance at the combustion chamber where the solid waste is fed and process of combustion releases heat 
which is converted to the gas and ash through chemical reactions. Three loading of municipal solid waste (MSW) incinerators were considered for this study; 100,150 and 200 $\mathrm{t} / \mathrm{d}$ with lower heating values (LHV) of 1000, 1700 and 2300 $\mathrm{kcal} / \mathrm{kg}$ for the simulation. The low quality waste compositions for the simulation were $59 \%$ moisture, ash $8 \%$ and combustible $33 \%$ [12]. The maximum excess air ratio was $1.76-2$ for the waste of high quality (LHV= $2300 \mathrm{kcal} / \mathrm{kg}$ ) and the minimum excess air ratio was 1.05-1.26 for the waste of low quality ( $\mathrm{LHV}=1000 \mathrm{kcal} / \mathrm{kg}$ ). This is necessary to maintain the furnace temperature exit within the range of $850-950^{\circ} \mathrm{C}$ to ensure complete combustion [12]. Yang et al. [12 reported that increasing the excess air results in decreasing the combustion gas. It is also worth mentioning that as reported by Yang et al. [12] carbon and hydrogen contents contribute to increase the heating value of waste material. In the waste material selected the carbon and hydrogen contents were $14 \%$ and $2.24 \%$, respectively.

The predicted results of the biomass simulation at different conditions are presented in Figures 3 through 19. In particular, Figures 3 and 6 depict the biomass output power at the ORC generator end as a function of the lower heating value (LHV) and flue gas flue rate for loading of $200 \mathrm{t} / \mathrm{d}$. It is quite evident that waste material with higher LHV increases the output power and similarly higher flue gas flow rates increases the biomass output power. Similar behavior was observed at other waste material loadings.

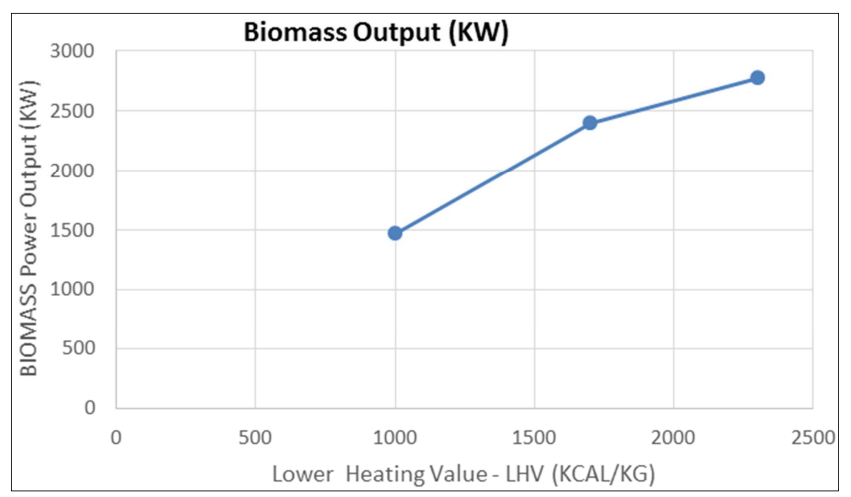

Figure 3. Biomass output power at $200 \mathrm{t} / \mathrm{d}$ biomass loading and different LHV.

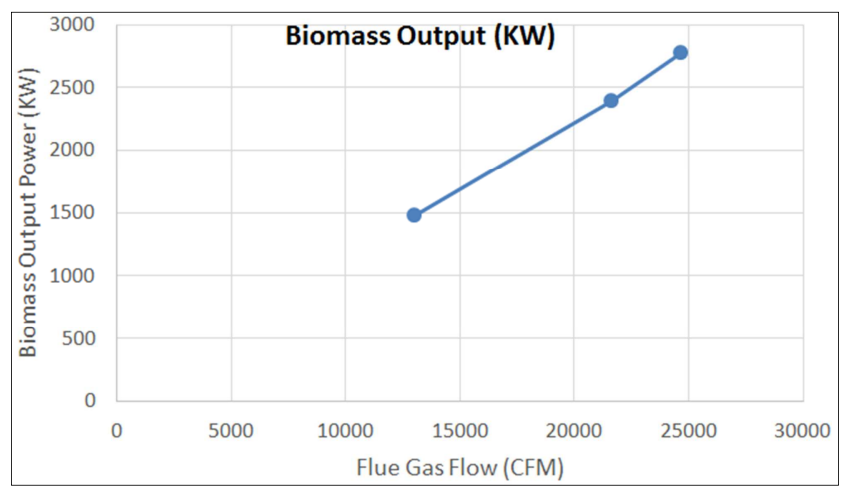

Figure 4. Biomass output power at 200 t/d biomass loading and different flue gas flows.
Furthermore, Figures 5 and 6 were constructed to show the impact of heating values and flue gas flow rates on the biomass energy conversion presented in the aforementioned model for biomass loading $200 \mathrm{t} / \mathrm{d}$. It is apparent from these figures that increasing flue gas flow rate and using material with higher heating values diminishes the biomass conversion efficiency. Similar behavior was observed with other biomass loadings. The results in figures show that the higher biomass heat supplied the higher output power generated at the ORC. Since higher and lower temperatures of the ORC do not change, only increasing the heat input at the incinerator increases the heat losses and consequently the biomass energy conversion efficiency.

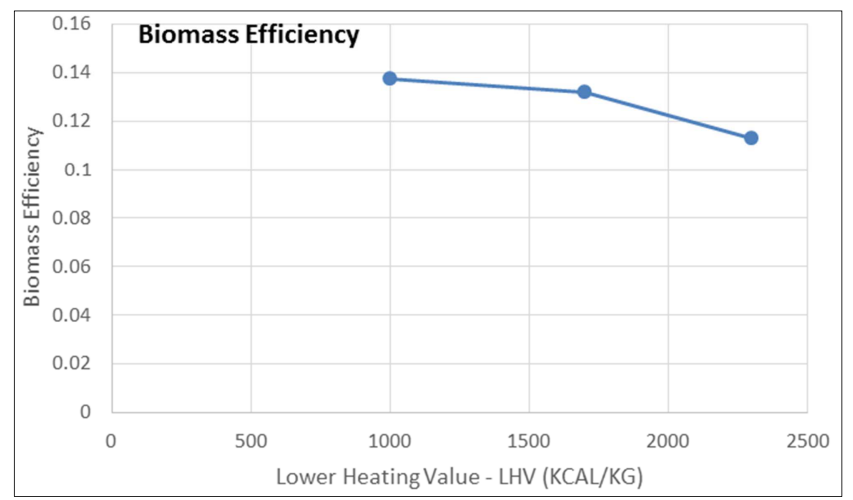

Figure 5. Biomass output efficiency at $200 \mathrm{t} / \mathrm{d}$ biomass loading and different $L H V$.

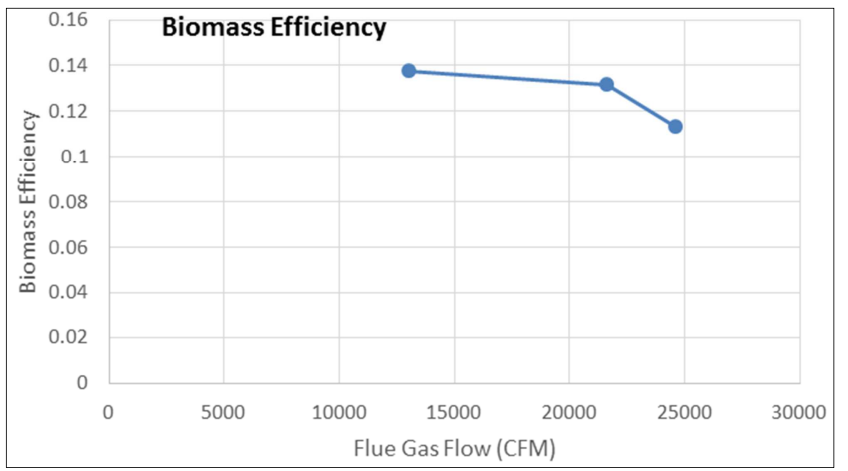

Figure 6. Biomass output efficiency at $200 \mathrm{t} / \mathrm{d}$ biomass loading and different flue gas flows.

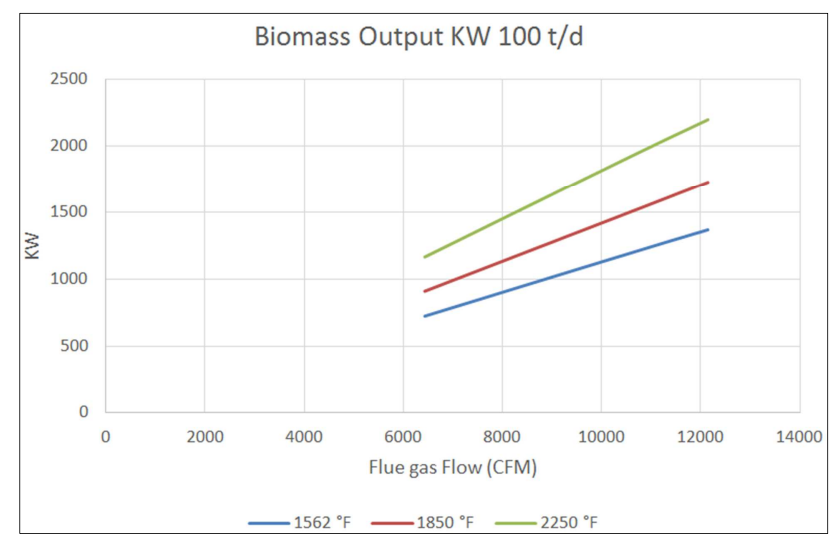

Figure 7. Biomass output power at $100 \mathrm{t} / \mathrm{d}$ biomass loading and different flue gas flows. 
The output and efficiency of lower biomass loading namely $100 \mathrm{t} / \mathrm{d}$, have been presented in Figures 7 through 9. It is quite evident from these figures that the biomass thermal behavior is similar to the $200 \mathrm{t} / \mathrm{d}$ presented in the previous figures. However, it appears from figures 7 and 8 that the biomass output is significantly influenced by the flue gas temperatures, flow rates and obviously the heating value of the biomass material. Furthermore, the results displayed in those figures show that the maximum biomass output is achieved at higher flue gas flow rates and temperatures.

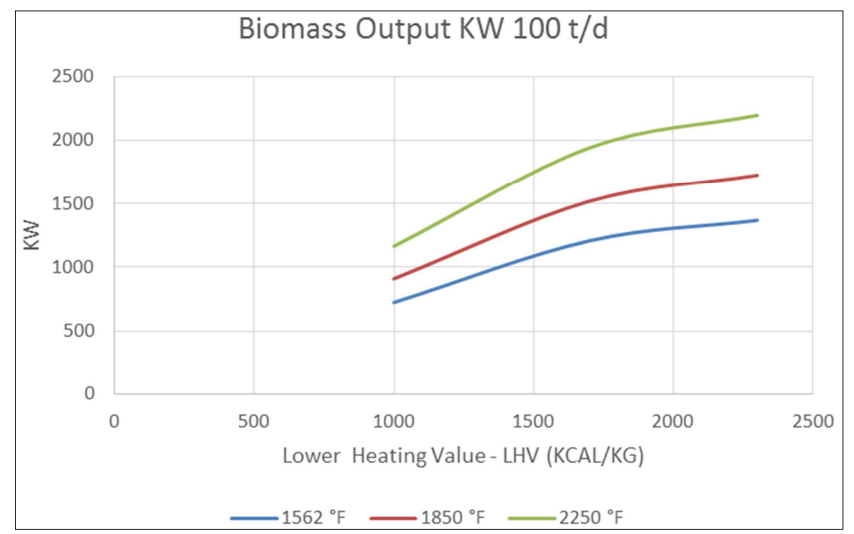

Figure 8. Biomass output power at $100 \mathrm{t} / \mathrm{d}$ biomass loading and different $L H V$

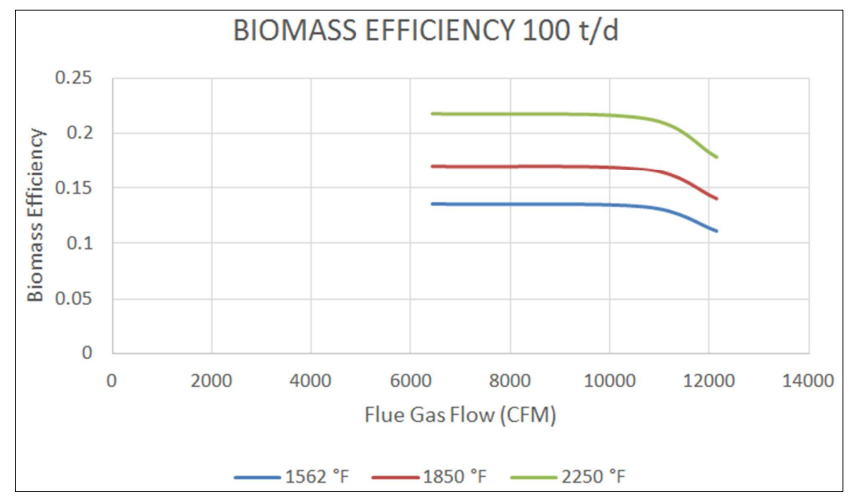

Figure 9. Biomass output efficiency at $100 \mathrm{t} / \mathrm{d}$ biomass loading and different flue gas flows.

On the other hand, Figure 9 has been constructed to show the major parameters that influence the biomass efficiency at $100 \mathrm{t} / \mathrm{d}$. The results displayed in that figure clearly show that the efficiency is maximized at efficient combustion that results in flue gas with higher temperatures. However, the results of this figure also show that integrated biomass system with CHP i.e. ORC has an efficiency that is limited by the thermodynamic and thermophysical properties of the refrigerant used in the ORC.

Furthermore, it is worthwhile noting that Figures 10 through 13 constructed for $200 \mathrm{t} / \mathrm{d}$, show that similar behavior has been observed with other biomass loadings. Furthermore, at each particular value of biomass loading, lower heating value (LHV) as well as specific flue gas flow rate, results show that the higher the flue gas temperature the higher the biomass efficiency.

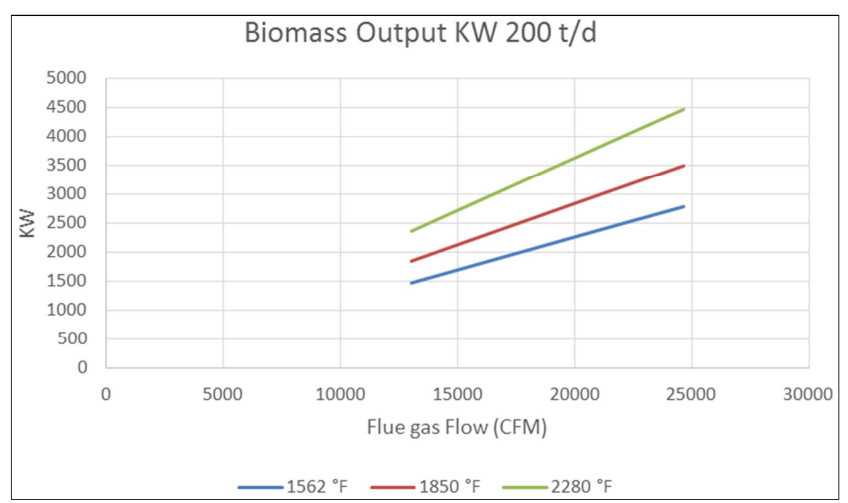

Figure 10. Biomass power output at different flue gas flows.

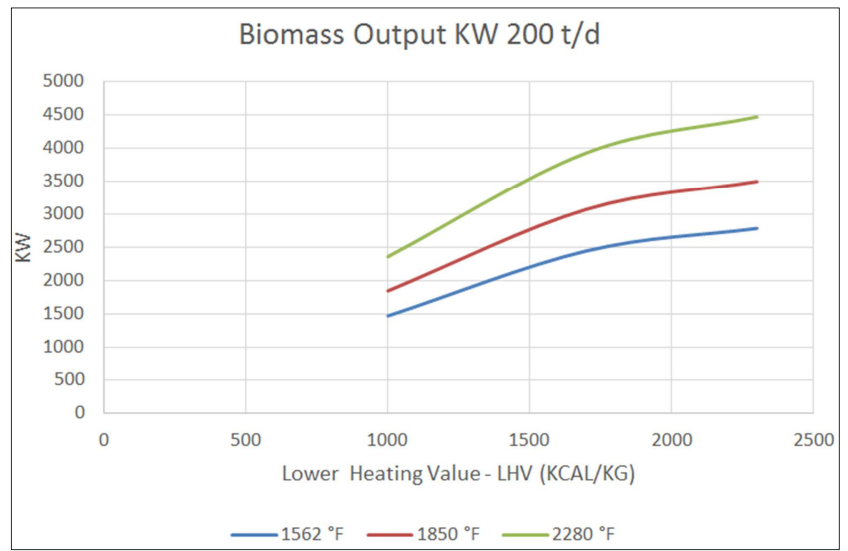

Figure 11. Biomass output power at different LHV.

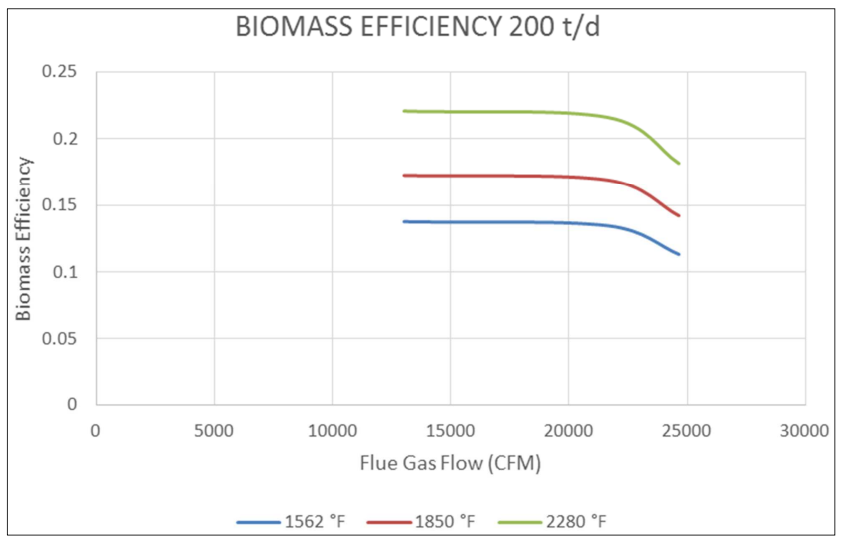

Figure 12. Biomass output efficiency at different flue gas flows.

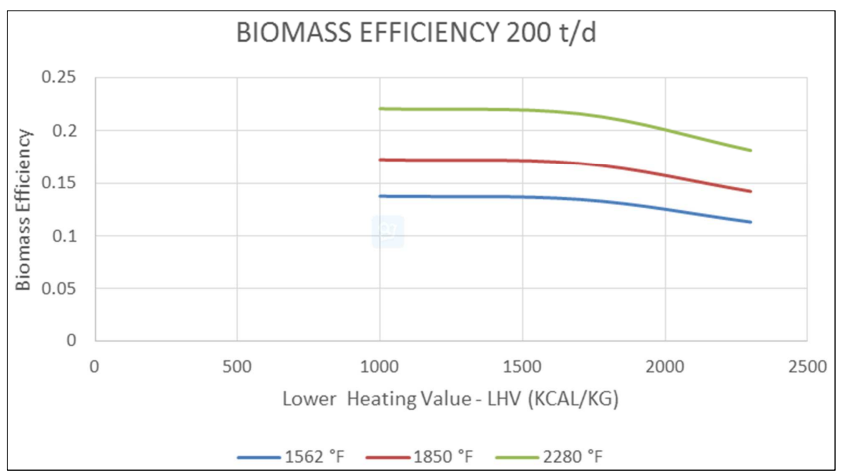

Figure 13. Biomass output efficiency at different $L H V$. 
Furthermore, in particular, Figure 14 has been presented to show the biomass integrated CHP output in terms of the biomass loadings at different flue gas temperatures. The results show that the higher the loading the higher the output power at the ORC generator end of the biomass integrated CHP hybrid system. As previously discussed, the higher the furnace gas exit temperature, around $2250 \mathrm{~F}, 2250 \mathrm{~F}$ results in higher biomass output power.

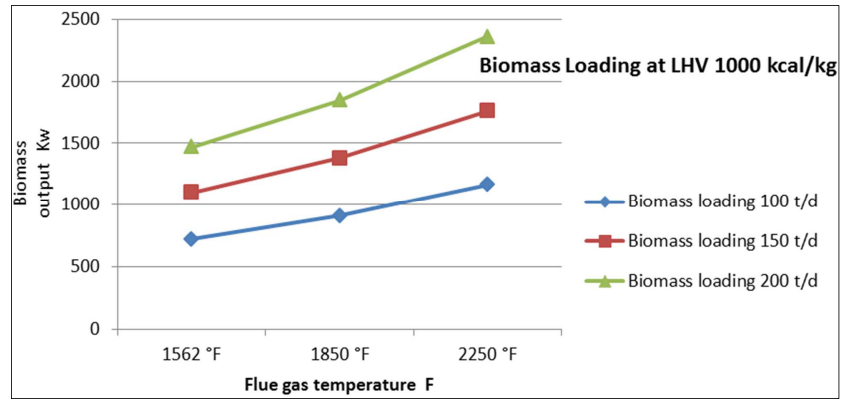

Figure 14. Biomass output power at different biomass loading.

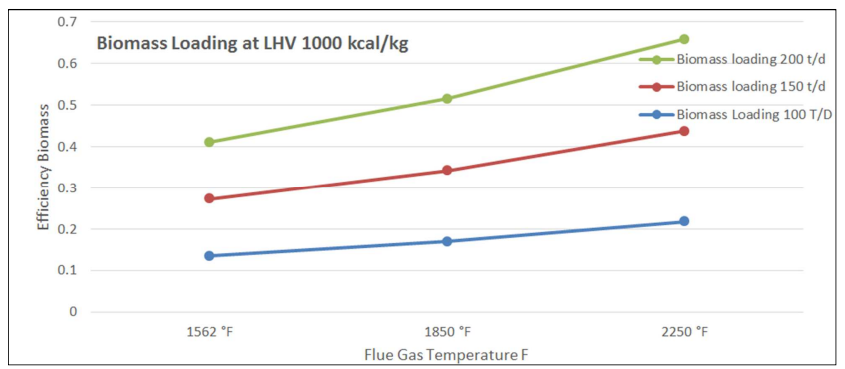

Figure 15. Biomass efficiency at different biomass loading.

Furthermore, in particular, Figure 15 has been presented to show the efficiency of biomass integrated CHP output in terms of the biomass loadings as well as different flue gas temperatures. This figure clearly shows that the higher the loading the higher the output efficiency of the biomass integrated CHP hybrid system. As previously discussed, the higher the furnace gas exit temperature, around $2250 \mathrm{~F}$, results in higher biomass efficiency since because of complete combustion and the destruction of incomplete combustion products (ICP) and full burning.

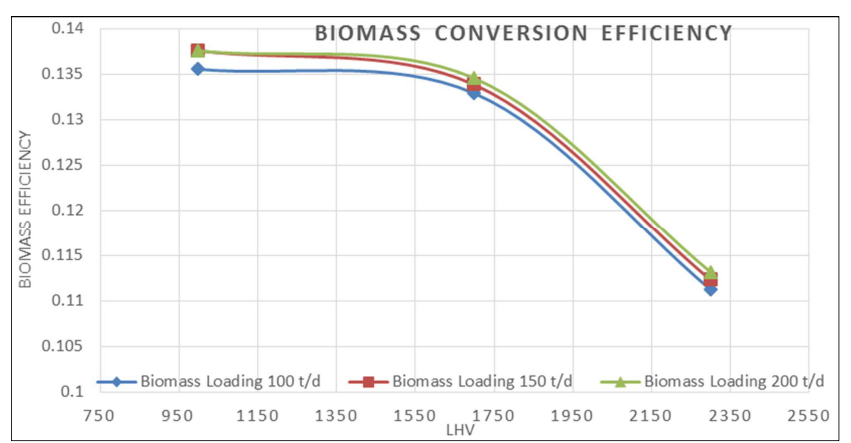

Figure 16. Biomass efficiency at different biomass loading.

However, Figure 16 also shows that the biomass conversion efficiency is impacted by the lower heating values (LHVs). And the figure also illustrates that at a particular lower heating value the higher the biomass loading the higher the efficiency. However, at lower LHV, the impact of the biomass loading is insignificant specially at $150 \mathrm{t} / \mathrm{d}$.

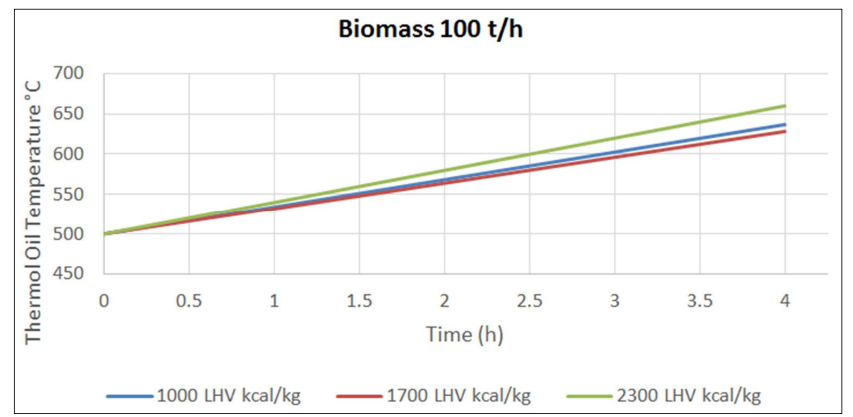

Figure 17. Dynamic behavior of thermal oil temperature at different biomass loading.

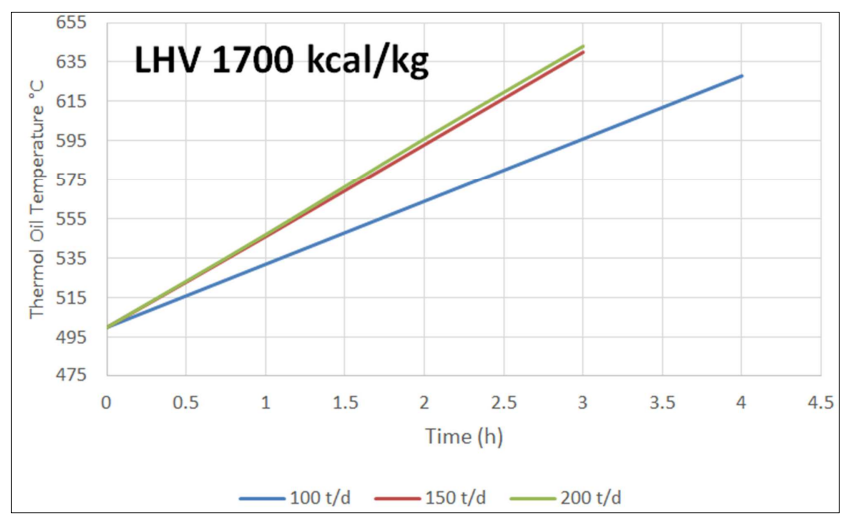

Figure 18. Dynamic behavior of thermal oil temperature at different $L H V$.

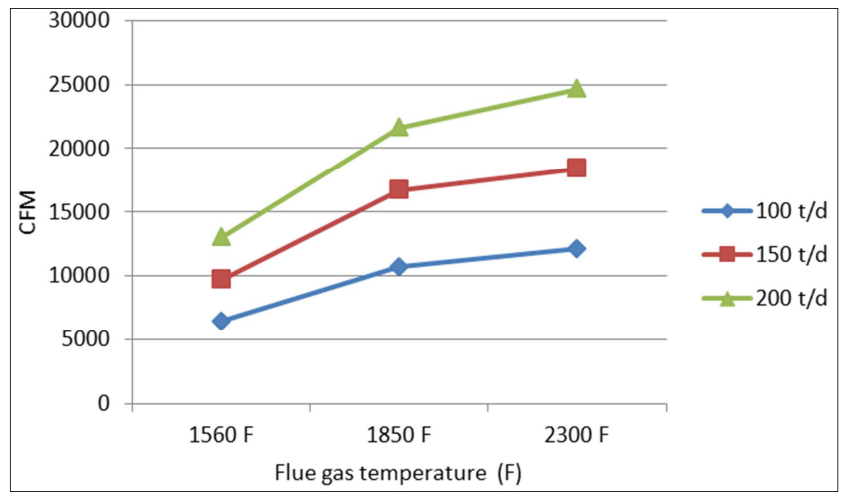

Figure 19. Flue gas flow rate at different loading (t/d).

The dynamic behavior of the thermal oil medium used to transfer the heat from the biomass flue gas to the ORC can be predicted by equation (11). The time-variation of the thermal oil temperature is shown in Figure 17 for $100 \mathrm{t} / \mathrm{d}$ biomass loading. It is quite clear from this figure that the maximum allowable temperature was achieved after 4 hours. This is important since beyond this temperature the Dow thermal oil considered in this simulation could disintegrate and compromise the heat transfer process in the Waste heat boiler as shown in Figure 1. Therefore, utmost attention should be given to the time-variation of the thermal oil temperature in the tank to avoid disintegration of the thermal oil. In addition, 
Figure 18 has been constructed to the behavior of the thermal oil temperature time variation at different biomass loading for LHV of $1700 \mathrm{kcal} / \mathrm{kg}$. As shown in this figure similar behavior has been observed, to results displayed in Figure 17, where the time to reach the upper limit of the thermal oil temperature before disintegration is between 3 to 4 hours depending upon the biomass loading.

Finally, in order to demonstrate the impact of biomass loading and flue gas temperatures on the flue gas mass flow rate, Figures 18 and 19 were constructed. It is quite evident that at a particular flue gas temperature, the higher the biomass loading the higher the flue gas mass flow rate. This is significant since the flue gas flow rate impacts the heat balance across the incinerator furnace and eventually the output power at the ORC turbine end and obviously the biomass hybrid system efficiency.

\subsection{Numerical Model Validation}

In order to validate our numerical model prediction described in equations (1 through 13) and numerically solved according to the Flow diagram displayed in Figure 2, we have constructed Figure 20 to compare between our model prediction and results presented by Yang [12]. Data on incinerators were unavailable in our laboratory, therefore, the data presented by Yang [12] were used for comparison purposes.

The data presented by Yang [11, 12] have excess air for waste low quality $(\mathrm{LHV}=1000 \mathrm{Kcal} / \mathrm{kg}$ ) of $1.05-1.26$. as previously mentioned theoretically increased excess air ratios decreases the temperature of the combustion gas. It is quite apparent from these data presented in Figure 20 that our numerical model fairly predicted the flue gas flow rate (Cubic Feet per minutes) at the outlet of incinerators and that heat up the thermal oil which drives the ORC to convert the heat of combustion into electrical power at the ORC shaft connected to the generator, switch gear and consequently the grid.

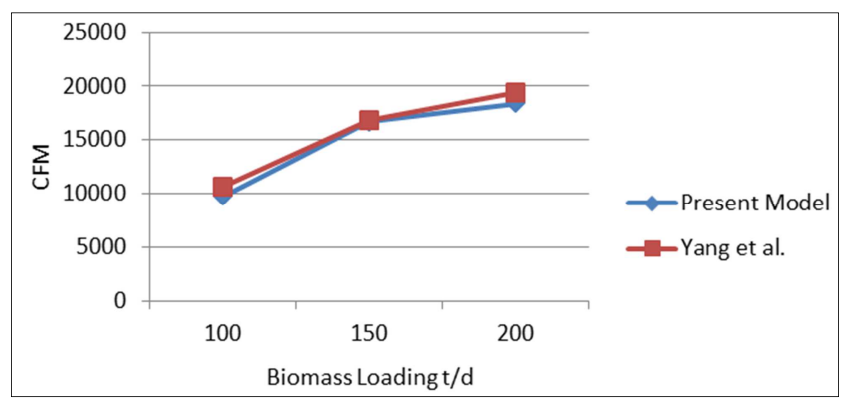

Figure 20. Comparison of present model and data by Yang [11, 12] at same excess air ratio of 1.05-1.26 and LHV 1700.

\section{Conclusions}

The energy conversion equations describing the heat and mass transfer mechanisms of a biomass and combined heat and power CHP/ORC hybrid system have been presented in time-variation formulations, integrated, coded and solved simultaneously for biomass incinerator type systems. The results show that increasing flue gas flow rate and using material with higher heating values diminishes the biomass conversion efficiency. Furthermore, the biomass output power is significantly influenced by the flue gas temperatures, flow rates and obviously the heating value of the biomass material. The model also shows that the dynamic variation of the thermal oil coolant temperature should be observed to avoid disintegration and compromise of the heat transfer process. Finally, the proposed model predicted results and compared fairly with data under various biomass loading conditions.

\section{Nomenclature}

A: Radiation surface area.

$C_{p_{\text {oil }}}:$ Specific heat of thermal oil

$C_{p}$ : Specific heat of Flue gas

$C V_{\text {bio }}$ : Calorific heat value of bio-gas

$E_{g}:$ Stefan Boltzmann Coefficient

$h_{w}$ : Convection heat transfer coefficient

$h_{1}$ : Enthalpy of refrigerant at vapor turbine entrance

$h_{2}$ : Enthalpy at exit of vapor turbine

$h_{4}$ : Enthalpy at inlet of waste heat boiler

$m_{\text {gas }}$ : Mass flow rate of flue gas

$m_{\text {bio }}$ : Biomass waste mass material

$m_{\text {ref }}$ : Mass flow rate ORC cycle refrigerant

$Q_{\text {comb }}:$ Combustion heat added

$Q_{\text {rad }}$ : Radiative heat

$Q_{\text {conv }}$ : Convective heat

$Q_{\text {evap }}$ : Evaporative heat

$Q_{W H B}$ : Heat transferred from thermal oil to refrigerant at the waste boiler heat exchanger

$\mathrm{Q}_{\mathrm{c}}$ : Heat released by condenser

$\mathrm{T}$ : Temperature thermal oil in heat exchanger tank

$\mathrm{t}$ : Time variation.

$V_{\text {tank }}$ : Volume of heater

$W_{O R C}$ : Work generated at ORC vapor turbine generator

$\mathrm{W}_{\mathrm{p}}$ : Work consumed by ORC pumps

Greek alphabet

$\eta_{O R C}:$ ORC thermal efficiency

$\eta_{\text {bio }}$ : Biomass furnace efficiency

$\delta_{\text {oil }}$ : Density of thermal oil

$\eta_{T G U}$ : Efficiency of turbine generating unit

$\eta_{W H B}$ : Efficiency of waste heat boiler
Subscripts:
comb-Combustion
conv-Convection
evap-Evaporation
gas-Flue gas
Oil-Thermal oil
ORC-Organic Rankine Cycle
ref-Refrigerant
rad-Radiation
WHB-Waste Heat Boiler 


\section{Acknowledgement}

The research work presented in this paper was made possible through the support of the Catholic University of Cuenca.

\section{References}

[1] Department of Energy, (2007), "Potential Benefits of Distributed Generation and Rate Related Issues that may Impede their Expansion, A Study Pursuant to Section 1817 of the Energy Policy Act of 2005".

[2] Binayak, B., Shiva, R. P., Kyung-Tae L., Sung-Hoon A., (2014),"Mathematical Modeling of Hybrid Renewable Energy System: A Review on Small Hydro-Solar-Wind Power Generation", International Journal of Precision engineering and Manufacturing-green Technology, Vol. 1, No 2, pp. 157173.

[3] KavithaSirasani, S. Y. Kamdi, (2013), "Solar Hydro Hybrid Energy System Simulation" International Journal of Soft Computing and Engineering (IJSCE), Volume-2, Issue-6, pp. 500-503, January 2013.

[4] Mustafa E., "Sizing and Simulation of PV-Wind Hybrid Power System", International Journal of Photoenergy, Volume 2013, ID 217526, pp. 1-10.

[5] Akikur, R. K., Saidur, R., Ping, H., Ullah, K. R., (2013), "Comparative Study of Stand-Alone and Hybrid Solar Energy Systems Suitable for Off-Grid Rural electrification: A review", Renewable and Sustainable Energy Reviews, Vol. 27, 738-752.

[6] Bhandari, B. (2014), "Design and Evaluation of tri-hybrid Renewable System (THRES)," Ph. D. Thesis, Department of Mechanical \& Aerospace Engineering, Seoul National University.

[7] Saha, N. C., Acharjee, S., Mollah, M. A. S., Rahman, K. T., and Rafi, F. H. M., (2013)," Modeling and Performance Analysis of a Hybrid Power System", Proc. of International Conference on Informatics Electronics \& Vision (ICIEV), pp. $1-5$.

[8] Fargali, H., M., Fahmy, F. H. and Hassan, M. A., (2008) “A
Simulation Model for Predicting the Performance of PV/Wind- Powered Geothermal Space Heating System in Egypt", The Online Journal on Electronics and Electrical Engineering (OJEEE), Vol. 2, No. 4.

[9] Mustafa, E., (2013), "Sizing and Simulation of PV-Wind Hybrid Power System", International Journal of Photoenergy, Vol 2013, Article ID 217526, 10 pages.

[10] Choi, S., Lee, J. S., Kim, S. K. and Shin, D. H. (1996), "Comparative Evaluation of Municipal Solid Waste Incinerators Design by Flow Simulation", Combustion \& Flame, Vol 106, 241-251.

[11] Yang, W, Shin, D., and Choi, S. (1998)" A Process Simulation Model for a 2 ton $/ \mathrm{hr}$. Incinerator (A Combined Bed Combustion and Furnace Heat Transfer Model), International Journal of Energy Research, Vol. 22, Issue 11, 943-951.

[12] Yang, W., Nam, Hyung-sik and Choi, S., (2007), "Improvement of Operating Conditions in Waste Incinerators using Engineering Tools", Waste Management, Vol 27, 604613.

[13] Gan, S., Goh, Y. R., Calkson, P. J., Parracho, A., Nasserzadeh, V. and Swithenbank, J. (2003), Formation and Elimination of Polychlorinated Dibenzo-p-Dioxins and Polycholrinated Debenzofurans from Municipal Solid Waste Incinerators", Combustion Science and Technology Vol. 175, 103-124.

[14] Sami, S., (2012) "Electric Power Generator Using a Rankine Cycle Drive with Refrigerant Mixtures and Exhaust Combustion Products as a Heat Source", US Patent No 8276383.

[15] Sami, S., (2013) "A Concept of Power Generator using Wind Turbine, Hydrodynamic Retarder and Organic Rankine Cycle Drive" JESE, Volume 5, No 2, March/April.

[16] Sami, S., (2011) "Behaviour of ORC low Temperature Power Generation with Different Refrigerants" International Ambient Energy Journal, Volume 32, No. 1.

[17] www.bios-bioenergy.at

[18] Bini, R., (2010), "State of the Art of ORC Technology for Biomass Plants" Expert workshop on Small Scale Biomass Technology Status market opportunity”, Copenhagen, October 7. 